\title{
SMART CITY
}

\author{
Gábor SZÖGI \\ Óbuda University College of Robotics, Budapest, Hungary, gabor.szogi@gmail.com
}

\begin{abstract}
The purpose of my research is to provide insight into the current state of smart cities. According to the everyday language, settlements use digital solutions for smart cities, which make life easier for people, who living there. The article demonstrates the impact on smart cities and how complex this concept is in practice. A smart city is constantly exploring and analysing the effects of the developments and innovations introduced.
\end{abstract}

Keywords: smart, IoT, surveillance, innovation.

\section{Introduction}

The term used in Hungarian for smart city is the mirror translation from English, which is, however, not an exact match for the English smart word, so the English term has a different flavour. The smart city is primarily considered as a system plan, which includes infrastructure investments, and secondly, an innovation project.

Unfortunately, a township does not turn out smart from one moment to the next, cooperations and well-organized services are needed for that. If this does not happen, the developments will not achieve their basic goal of making the lives of the people living there livelier and better.

According to the International Telecommunication Union study, "The Sustainable Smart City is an innovative city that improves the quality of life of city dwellers and the efficiency of city operations through information technology and other tools. This creates the competitiveness of the settlements by providing current and future generations with the economic, social and environmental needs of urban life."[1]

\section{The basics of smart city}

According to Boyd Cohen, six pillars of smart cities can be distinguished. In addition to the following general considerations, the identification of specific indicators related to the specific de- velopment goal of a given city may also be necessary when elaborating a development strategy or monitoring performance. [2, 3, 4]

\subsection{Smart economy}

Smart economy means services supporting businesses and innovation ecosystems, as well as productivity training, entrepreneurship and the incubation environment, tools to help local and global market integration of businesses, information and communication technology platforms, and open data.

\subsection{Smart traffic}

In the case of smart transport, mobility growth is proportional to the technological development of transportation. By further developing traditional transport systems, intelligent transport systems can be created, also known as Intelligent Transportation System (ITS). This can mean service-oriented transport development and the provision of multimodal access, that is, the establishment of system-level connections between various transport branches.

\subsection{Smart environment}

The smart environment encompasses smart buildings, meaning sustainable environmental management through the climate-friendly city, where the energy-efficient design of the built environment is important. 


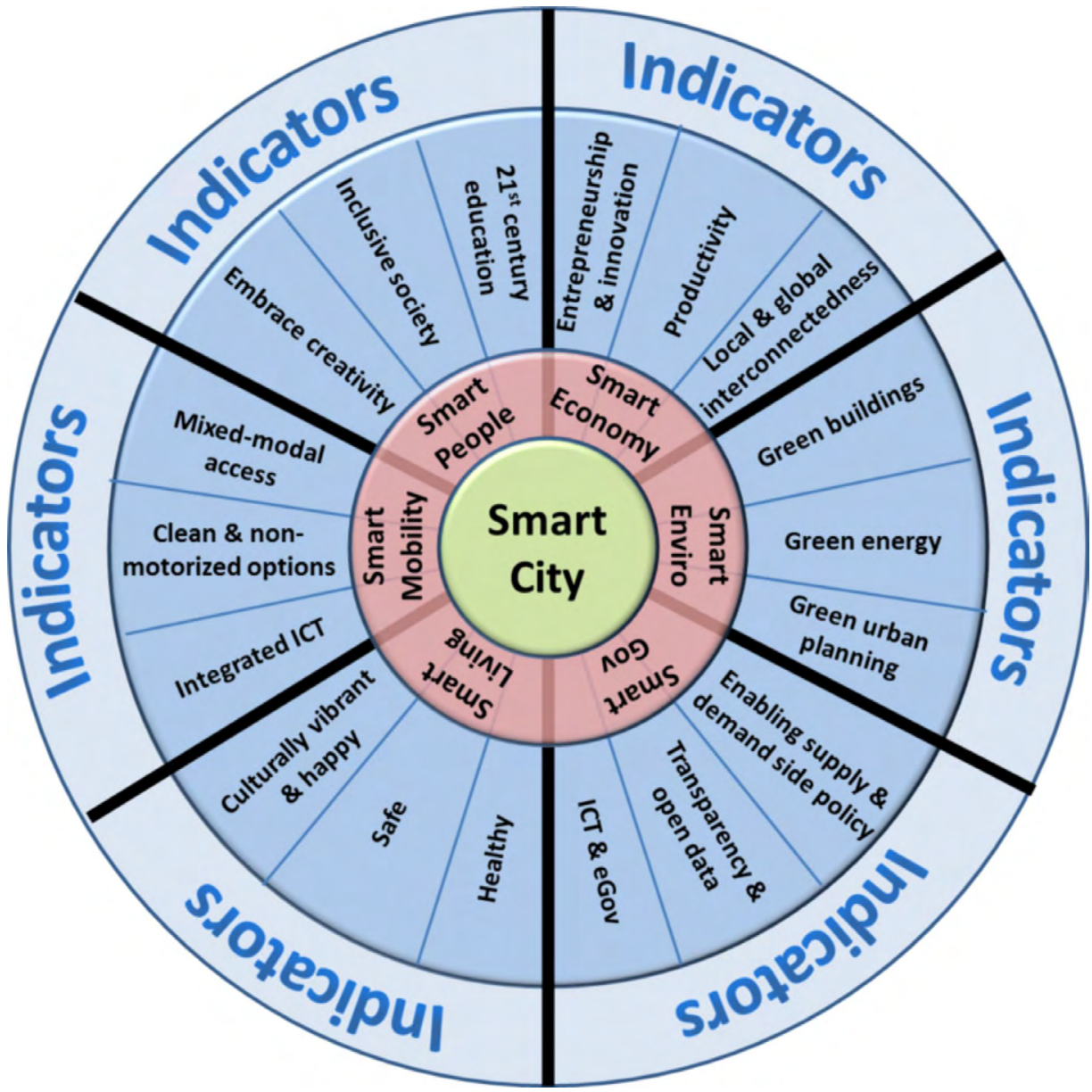

Figure 1. Smart capital pillars [5]

\subsection{Smart living conditions}

Under smart living conditions, we understand the well-being, safety and health of the members of society, where vital city and personal safety and health improvement measures are important.

\subsection{Smart people}

Smart people are representing as a pillar the awareness, human capital and social capital, where inclusion and integration are important, as well as education, training and creativity.

\subsection{Smart government}

Smart governance means open, transparent and participatory decision-making processes. This includes information and communication technology based support, personalized urban and public services, data management measures and developer-oriented, innovative governance.

\section{Technical features and challenges}

The complexity of technology and service ecosystems in smart cities require a holistic approach. Considering the trends in information and communication technology, there are a number of dilemmas that make difficult to develop smart city system designs. [6]

\subsection{Network and communication}

A critical point is that a number of technological trends are linked to the communication infrastructure on which smart cities are based, enabling people and devices to connect and to collect data for monitoring in order to develop later services. Depending on the needs of a smart city, data transfer is possible through various wireless technologies, such as bluetooth, Zigbee. and WIFI. 


\subsection{Low energy WAN technology}

Adapting to technological capabilities for personal and local networking technologies, the use of existing 3 / 4G networks and future 5G technology in smart cities is another feature. These technologies use non-licensed spectrum and focus on low energy consumption and cost.

\subsubsection{IPv6}

"Internet Protocol version 6 (IPv6) is a new version of Internet Protocol (IP) designed to replace Internet Protocol version 4 (IPv4).

The essence of the research initiated by the IETF (Internet Engineering Task Force) was to foresee the foreseeable depletion of version 4 (IPv4) titles for the development of the new protocol. As the number of Internet users and the number of devices they use is expanding, the number of IP addresses that can be issued is decreasing. "[7]

IPv6 in addition to replacing the current dynamic IP address allocation, so each end user can get a fixed IP address, it also brings innovations to security in relation to current IPv4. The 128bit address space provides thousands of billions of devices with an IP address, so it is virtually inexhaustible capacity. Translating this into households, every home-based device can get a separate IP address in homes, so they can communicate with each other without disturbance, which is a prerequisite for a smart city system plan.

\subsubsection{3/4G evolution}

Nowadays, many important initiatives focus on the use of existing 3 / 4G technologies in smart cities, although there is significant activity in the standardization and deployment of the $5 \mathrm{G}$ network, which plans to complete its deployment by 2020.

\subsubsection{G network}

The planned 5G network would work with greater bandwidth than the current $4 \mathrm{G}$, thereby providing greater coverage for broadband mobile networks and supporting extensive machine communication between devices. One of the goals of $5 \mathrm{G}$ 's research and development is to reduce network latency and energy consumption, which creates the Internet's intrinsic development of the objects, which is a prerequisite for a smart city concept. [8]

\subsection{Cyber Physical Systems and IoT}

Cyber Physical System (CPS) is a link between virtual environment and physical systems, and the Internet of things (IoT), it is generally defined by the fact that each device is networked with each other that is needed to form smart cities. The infrastructure of the present cities has been monitored for years, such as electricity grid and traffic, but the IoT can optimize it considerably. This is a good example for electricity grids, when electricity is higher than consumption, consumers can switch to controlled households in order to balance electricity production equilibrium.

\section{Conclusions}

As the result of the research, we can conclude that the smart city concept is a huge project with a large number of contributing developers. In the developed world there is a change of view in terms of urban development. There are many positive processes and developments in cities around the world, such as modernization of energy or transport infrastructure, but far from the ideal. By linking and monitoring services, enormous databases are created, which, by evaluating and using them, will later be used to carry out a separate research.

\section{Acknowledgments}

I would like to thanks the College of Robotics at Óbuda University, for which I have received numerous professional and financial support for my present scientific work. The College offers outstanding help to talented students and PhD students at Óbuda University.

\section{References}

[1] ITU: Smart sustainable cities: An analysis of definitions, 2014., p. 13.

https://www.itu.int/en/ITU-T/focusgroups/ssc/ Documents/Approved_Deliverables/TR-Definitions.docx

[2] B. Cohen: The Smartest Cities In The World. 2015. https://www.fastcompany.com/3038818/thesmartest-cities-in-the-world-2015-methodology

[3] Lechner Tudásközpont. Smart City tudásplatform. Metodikai javaslat. 2015.

http://lechnerkozpont.hu/doc/okos-varos/ smart-city-tudasplatform-metodikai-javaslat. pdf

[4] Okos Város. 2018 http://okosvaros.lechnerkozpont.hu/hu/ 
[5] S. F. DeAngelis: Thought Probe Series on Tomorrow's Population, Big Data, and Personalized Predictive Analytics: Part 1, Getting Started. 2013 https://enterpriseresilienceblog.typepad.com/enterprise_resilience_ man/2013/04/a-thought-probe-series-on-tomorrows-population-big-data-and-personalized-predictive-analytics-part-1.html
[6] L. Rodger: Smart Cities. An Overview of the Technology Trends Driving Smart Cities, IEEE 2017. march.

[7] Internet Society. 2018. https://www.internetsociety.org/issues/ipv6/

[8] Osseiran, A. (2014. május 1.). Scenarios for $5 G$ mobile and wireless communications: the vision of the METIS project. IEEE Communications Magazine 52 (5), 26-35. o.

https://doi.org/10.1109/MCOM.2014.6815890 